\title{
Effect of Stone Enhancer on Marginal Fit of Nickel Chromium Cast Copings
}

Suman Thotapalli*

Lecturer, Division of prosthodontics, Riyadh colleges of dentistry and pharmacy, Riyadh, Saudi Arabia

\begin{abstract}
Aims: The ringless casting procedure is in use in clinical dentistry although there is not adequate scientific data to support its use in pattern fabrication using different die materials. The purpose of the study was to compare vertical marginal discrepancy of cast copings fabricated on two die materials cast using ringless casting technique.

Materialsand methods: Two groups of cast copings were fabricated after investing patterns in phosphate bonded investments mixed using standard liquid/water ratio. The vertical marginal discrepancy ofnickel chromium cast copings which were cast after fabrication on two die materials (type IV die stone, Epoxy-it) using Ringless casting technique was determined and the Mean Vertical marginal Discrepancy was calculated based on measurements made with a Travelling Microscope.

Results: The mean and standard deviation for each side was calculated. One way ANOVA and paired t-testwas performed to identify statistically significant difference between the groups. The results of the study showed marginal discrepancy values of $38 \mu \mathrm{m}$ and $37 \mu \mathrm{m}$ for type IV die stone and Epoxy-it die materials cast using the ringless casting system.

Conclusions: The purpose of the study was to compare vertical marginal discrepancy of cast copings fabricated on two die materials cast using ringless casting technique. The results showed no statistical significance when using the two die materials and stone enhancers can be used as an alternative to improve the accuracy of cast copings.
\end{abstract}

Keywords: Marginal discrepancy; Ringless casting technique; Die materials; Stone enhancers

\section{Introduction}

A good marginal fit is important in dental restorations to fulfill biologic, physical and cosmetic requirement [1]. The accuracy of fit of casting is affected by the quality of preparation (undercuts, taper of preparation), the impression, and the working cast, the quality of wax used for lost wax technique and by the accuracy of the casting [2], Which in turn is affected by shrinkage ofalloy during solidification. Use of a metal ring in conventional casting methods limits this expansion since the metal ring expands less than the investment. An alternate method is the use of the ring less casting technique. This technique has been made possible by the introduction of phosphate bonded investments which can withstand high temperatures of casting base metal alloys and do not require a metal ring for protection $[3,4]$.

Lombardas et al. [2] observed that the castings obtained with the ring less technique provided less vertical margin discrepancy than the castings produced with the conventional metal ring technique. In an effort to overcome the disadvantages of type IV stone die and epoxy resin die materials a new stone enhancing liquid has been introduced which can be used as gauging liquid for conventional type IV stone die material. The polymers of the liquid help bond gypsum particles together making gypsum less brittle and more resistant to chipping.

The aim ofthe present invitro study was to compare the vertical marginal discrepancy of single full coverage nickel chromium cast copings fabricated on two different types ofdie (type IV stone die, Epoxy-it) materials and cast using ring less casting techniques.

\section{Materials and Methods}

\section{Fabrication of stone dies}

A typhodonttooth form (Nissin Dental Productcinc. , Kyoto, Japan) of a mandibular first molar was prepared to receive a metal ceramic crown with a $6^{\circ}$ taper and a straight shoulder finish line [5]. The ivorine tooth form was fixed in the base that is provided by the manufacturer during preparation. This prepared tooth form was then duplicated using a technique described by Mekayarajjananonth and Huband [6]. A small self cure acrylic container was cut into two parts. The upper portion containing the lid was used for the duplication procedure. This was about $2 \mathrm{~cm}$ high. The prepared typhodont tooth form was placed in the center of the lid and stabilized using sticky wax. Light body poly

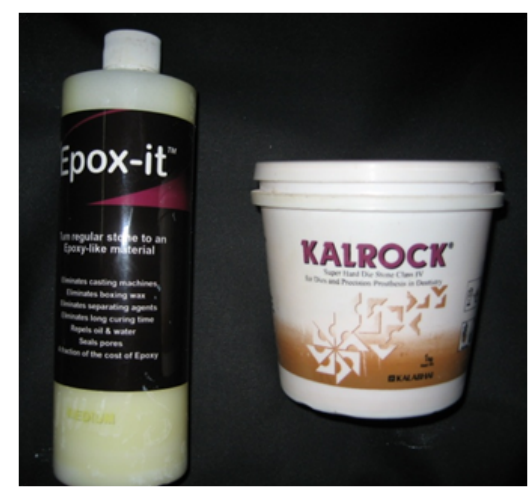

Figure 1: Die materials.

*Corresponding author: SumanThotapalli MDS, PGHDM, Lecturer, Division of prosthodontics, Riyadh Colleges Of Dentistry and Pharmacy, Riyadh, Saudi Arabia, Tel: +966544868463; E-mail: suman. thotapalli@riyadh. edu. sa

Received May 25, 2013; Accepted June 03, 2013; Published July 07, 2013

Citation: Suman T (2013) Effect of Stone Enhancer on Marginal Fit of Nickel Chromium Cast Copings. Anaplastology 2: 114. doi: 10.4172/2161-1173.1000114

Copyright: (c) 2013 Suman T. This is an open-access article distributed under the terms of the Creative Commons Attribution License, which permits unrestricted use, distribution, and reproduction in any medium, provided the original author and source are credited. 
vinyl siloxane was syringed on and around the prepared tooth form. The remaining space in the container was filled with putty material. The material was allowed to set. The cap of the container was opened and the typhodont tooth form was removed from the impression mould. The mould was inspected for acceptable surface detail before pouring a die material.

Types IV die stone and Epoxy-it (Epoxt-it, Cbite. inc, VA, USA) (Figure 1) were mixed according to manufacturer's directions and poured into the impression mould until the entire mould was filled. The die material was allowed to set and the stone duplicate of the prepared typhodont tooth form was removed from the mould. The stone die was placed on a surveyor table and a tapered tool was used to check for uniformity of taper. Successive pours of die material was done in the same mold to obtain individual replicas of prepared tooth.

\section{Fabrication of plastic patterns}

The patterns for the cast copings were fabricated using Adapta deep drawing system (Bego Wilh Herbrt GMbh Co, Brener, Germany). 20 such patterns were fabricated and divided into two groups of 10 patterns each as follows (Figures 2 and 3 ). The patterns were numbered and symbolically represented to all seating of copings on the same die.

\section{GROUP I-DIE STONE}

\section{GROUP II-EPOXY- IT}

\section{Investing and casting the wax pattern}

The patterns were invested individually in a rubber casting ring using phosphate bonded investment. The combination of silica sol special liquid (Beg sol, Bego)/distilled water ratio as specified by manufacturer was used to mix the investment (Bellavest $\mathrm{T}$, Bego). Each coping was invested individually in a rubber ring immediately after fabrication. The investment was hand mixed for 15 to $20 \mathrm{sec}$ and then mixed for $30 \mathrm{sec}$ in a vacuum mixer. The investment mouldwas removed from the rubber casting ring $10 \mathrm{~min}$ after mixing and allowed to undergo unhindered setting expansion for $60 \mathrm{~min}$ for the ringless technique. The moulds were then transferred to a burnout furnace and Burnout was completed at a temperature of $910^{\circ} \mathrm{C}$. The moulds were now transferred to a induction casting machine for casting using nickel chromium alloy (Wironit, Bego).

The investment was allowed to cool for 2 hours before divesting. Gross divesting was done using a rubber hammer and the remaining investment was removed by sand blasting with $50 \mu \mathrm{m}$ aluminum oxide and then steam cleansed. The internal surface of the castingswas trimmed to remove any blebs or gross irregularities. No extensive

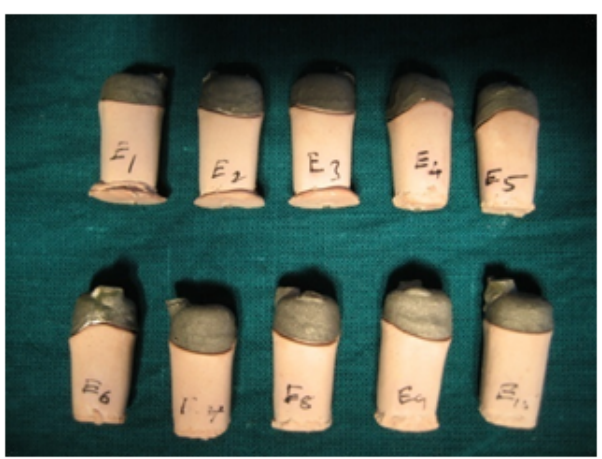

Figure 2: Epoxy-it trimming of the internal surface was done to fit the copings. 10 such copings were obtained for each of the two die systems.

The copings were seated on the stone die/epoxy die using only finger pressure. The vertical marginal discrepancy was measured using a Travelling microscope at a magnification of 10X (Figure 4). The distance between any two points was measured by first observing the readings for the points on the vernier scale (calculated by the formula MSR+(VSCxLC) $\mathrm{cm}$ where MSR=Main Scale Reading, VSC=Vernier Scale Coincidence and LC=Least Count which is $0.001 \mathrm{~cm}$ ) and the subtracting one from the other. Four measurements were made randomly on each of the buccal, mesial, distal and lingual surfaces of the die, totaling to 40 readings per group. A stone base sample holder was constructed to hold the major axis of the metal die parallel to the focal plane to minimize errors due to out of plane rotation. The results were subjected to statistical analysis.

\section{Results}

The mean and standard deviation for each group was calculated. One way ANOVA was performed to identify statistically significant difference between the different groups and Student $\mathrm{T}$ test for significant difference in between two groups.

The mean discrepancy values for the ringless system are $38 \mu \mathrm{m}$ and $37 \mu \mathrm{m}$ for groups I and II respectively (Table 1 ). The calculated t-value (0. 42), $\mathrm{p}>0.01$ which is not significant. Hence it was concluded that there was no significant difference between die stone and Epoxy-It copings using the ring less casting system (Chart 1).

\section{Discussion}

Precise fit of the restoration margin to the preparation margin is a necessary condition to prevent gingival inflammation and failure of restoration [7], as it allows for less plaque accumulation at the

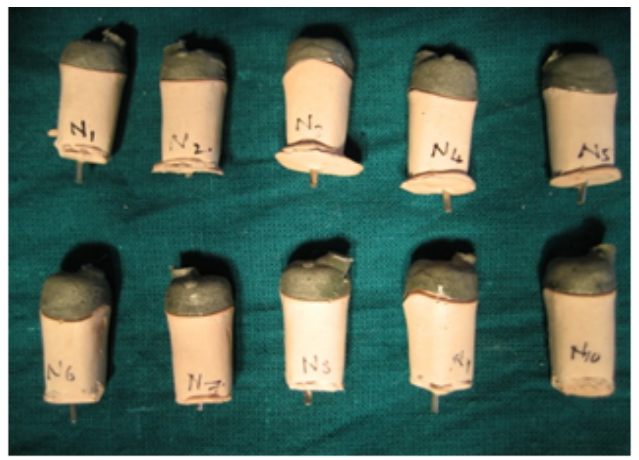

Figure 3: Die stone.

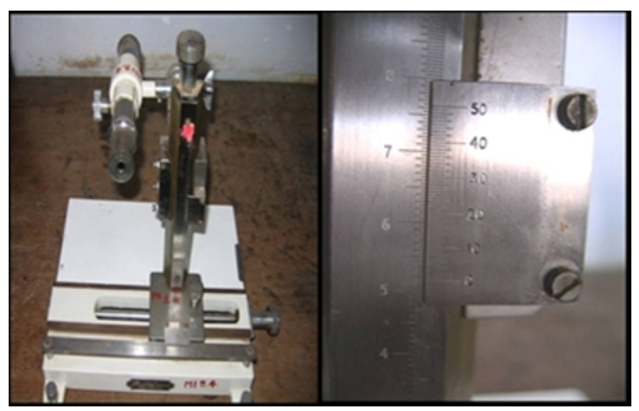

Figure 4: Travelling microscope. 
marginal area, provides better mechanical properties, less cement space and improves the aestheticresults. The present study was undertaken to evaluate the effect of different die materials on the fit in terms of vertical discrepancy. The mean vertical marginal discrepancy values obtained were in accordance with one similar study on ringless casting technique [2].

The mean discripency values obtained were in the range of 37$38 \mu \mathrm{m}$ which was within the clinically acceptable range of $50 \mu \mathrm{m}$ [8]. This may be due to the use of spacer during fabrication of copings and the thickness of spacer was standardized by the use of plastic pattern forming (Adapta deep drawing, Bego, Germany) system. The spacer foil in this system provided a uniform thickness of $0.1 \mathrm{~mm}$ and coping thickness of $0.6 \mathrm{~mm}$ which on heating and adaptation stretches to the desired thickness of $0.3 \mathrm{~mm}$ [9]. This uniform thickness of spacer helps prevent the binding of the casting to the axial walls as observed by Lombards et al. [2].

The use of ringless casting technique has been made possible by the introduction of phosphate bonded investments which can withstand high temperatures of casting base metal alloys and do not require a metal ring for protection [3,4]. Hutton and Marshall [10] stated that expansion is also dependent on the silica content of the liquid. This has been proportioned at $70 \%$ liquid to water ratio as stated by manufacturer for Bellavest-T phosphate bonded investment (BegoWilh Herbst GmBH Co, Brener, Germany).

Die materials used for the fabrication of cast metal restorations by an indirect technique should be durable, dimensionally accurate and show good reproduction of detail. Cost and ease of manipulation are other factors are important in guiding the selection of a die material [11]. Various materials like gypsum die stone, silver plated dies \& epoxy resin die materials are widely used. The literature concerning the dimensional accuracy of various die materials is somewhat equivocal. Gypsum die materials generally exhibit an average setting expansion of $0.01-0.1 \%$ [12-14]. Such minimal expansion is thought to be beneficial in terms of aiding compensation for metal shrinkage, wax pattern dimensional change [12].

Epoxy resin dies have been found to be generally undersized primarily because of polymerization shrinkage [15]. Vermilyea et al. [16] investigated three resin-based die materials that demonstrated hardness and tensile strength superior to gypsum. The manufacturers of new generation epoxy resin die systems claim to have controlled this shrinkage and that dimensional accuracy can be precisely controlled. In

\begin{tabular}{|c|c|c|c|c|c|c|}
\hline Group & N & Mean $(\boldsymbol{\mu m})$ & SD & SE & t-value & LS \\
\hline Die Stone & 40 & 38 & 0.010 & 0.017 & 0.42 & NS \\
\hline Epoxy & 40 & 37 & 0.093 & 0.015 & & \\
\hline
\end{tabular}

Table 1: Showing t-value for ringless/die stone and ringless/epoxy $(\mu \mathrm{m})$.

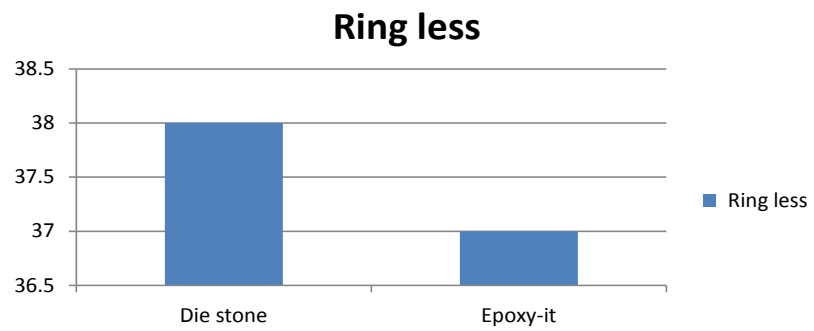

Chart 1: Difference between die stone and Epoxy-It copings using the ring less casting system. light of such conflicting evidences the present study was undertaken to compare the accuracy of casings fabricated using new stone enhancer liquid (Epoxt-it, Cbite. inc, VA) which is claimed to produce properties comparable to epoxy resin die materials with type IV dental stone die material (Kalrock, Kalabhaikarson, Mumbai).

The two die materials used in the present study exhibited vertical marginal discrepancy values in the range of $50 \mu \mathrm{m}$ [8] for clinical acceptability when cast using ringless casting technique. These values of $37 \mu \mathrm{m}$ and $38 \mu \mathrm{m}$ for the Epoxy-it and type IV die stone respectively; cast using the ringless casing technique.

Two way ANOVA proves that the mean vertical discrepancy of die stone and epoxy- it groups were significantly less and well with-in the range of acceptable clinical discrepancy of $50 \mu \mathrm{m}$ when using the ring less casting techniques.

The results indicated better marginal fit when utilizing the ringless casting technique similar to a study where, an additional variable of stone die with the new stone enhancer yielded results comparable to conventional type IV stone die material [2]. The current study tried to reproduce the exact clinical situation by using the stone dies rather than standard metal die, using a plastic spacer technique to standardize the thickness of the spacer and the cast coping. The stone enhancer used in the study yielded results comparable to the type IV stone for clinical acceptability.

\section{Conclusion}

No significant difference of the vertical margin discrepancy between the copings fabricated on die stone and Epoxy-it. The discrepancy values were within the normal clinically acceptable range of $50 \mu \mathrm{m}$. Evaluate dimensional accuracy, abrasion resistance and detail reproduction of the new enhancer stone die material. Further studies may be conducted to evaluate the absolute marginal discrepancy when used with multiple fixed partial dentures and Implant frame work fabrication.

\section{References}

1. Assif D, Antopolski B, Helft M, Kaffe I (1985) Comparison of methods of clinical evaluvation of the marginal fit of complete cast gold crowns. J Prosthet Dent 54: $20-24$

2. Lombardas P, Carbunaru A, McAlarney ME, Toothaker RW (2000) Dimensiona accuracy of castings produced with ringless and metal ring Investment system. J Prosthet Dent 84: 27-31.

3. Kenneth J Annusavice (2003) Phillips Science Of Dental Materials, (11thedn) St Louis, Missouri, USA. 309-319.

4. William J O'brien (2002) Dental Materials And Their Selection, (4thedn) Quintessence Publishing Co, Inc258-262.

5. Hunter AJ, Hunter AR (1990) Gingival crown margin configuration : A review and discussion. Part 1: Terminology and width. J Prosthet Dent 64: 548-552.

6. Mekayarajjananonth T, Huband ML (2000) Simplified Duplicating Procedure For Dental Casts. J Prosthet Dent 84: 370

7. Richter WA, Ueno H (1973) Relationship between crown margin placement in inflammation. J Prosthet Dent 30:156-159.

8. Jenkins CBG, Phillips RW (1971) An evaluation of five Inlay investing techniques employed with different types of wax patterns. J Prosthet Dent 23: 211-220.

9. Shillinburg HT, Hobo S, Whitsett LD (1997) Fundamentals of Fixed Prosthodontics, (3rdedn) Quintessence publishing.

10. Hutton JE, Marshall GW (1993) The expansion of phosphate bonded investments: Part I-Setting expansion. J Prosthet Dent 70: 121-125. 
Citation: Suman T (2013) Effect of Stone Enhancer on Marginal Fit of Nickel Chromium Cast Copings. Anaplastology 2: 114. doi: 10.4172/21611173.1000114

Page 4 of 4

11. Yamen P, Brandau HE (1986) Comparison of three epoxy die materials. J Prosthet Dent 55: 328-331.

12. Bailey JH, Donovan TE, Preston JD (1988) The dimensional accuracy of improved dental stone, silverplated and epoxy resin die materials. J Prosthet Dent 59: 307-310.

13. Price RB, Gerrow JD, Sutow EJ, Mac Sween R (1991) The dimensional accuracy of 12 impression material and die stone combinations. Int J Prosthodont 4: 169-174.
14. Chaffee NR, Bailey JH, Sherrad DJ (1997) Dimensional accuracy of improved dental stone and epoxy resin die materials. Part I : Single die. J Prosthet Dent 77: 131-35.

15. Nomura GT, Reisbick MH, Preston JD (1980) An investigation of epoxy resin dies. J Prosthet Dent 44: 45-50.

16. Vermilyea SG, Kuffler MJ, Tamura JJ (1983) Casting Accuracy of basemetal alloys. J Prosthet Dent 50: 651-653. 